\title{
ИССЛЕДОВАНИЕ ДЕСОРБЦИИ СПИРТОВ С ПОВЕРХНОСТНЫХ ОКСИДОВ ПОЛУПРОВОДНИКОВ ТИПА ${ }^{\amalg}{ }^{\amalg} B^{V}$
}

\author{
(Представил О. Киррет)
}

На стабильных и воспроизводимых поверхностях арсенида и фосфидов галлия и индия преобладающими соединениями являются оксиды катионного компонента, т. е. оксиды галлия и индия [1, 2]. Количество и характер примесей после химической обработки частично определяются адсорбционными и каталитическими свойствами этих оксидов.

В процессе травления и промывания полиметаллидных полупроводниковых материалов используют органические растворители, в частности спирты, которые применяют в качестве компонентов травителей или обезжиривающих и осушающих агентов [3].

Исследование малоизученного процесса десорбции спиртов с поверхностных оксидов некоторых полупроводников типа $\mathrm{A}^{\mathrm{III}} \mathrm{B}^{\mathrm{V}}$ (оксидов металлов III группы) представляет большой практический и теоретический интерес, так как указанные соединения являются активными катализаторами дегидратации и дегидрирования спиртов $\left[{ }^{4}\right]$, а также хорошими адсорбентами. Однако недесорбированные спирты и продукты их разложения могут сильно влиять на электрофизические свойства поверхности полупроводников [5].

В настоящей работе представлены результаты исследования термодесорбции спиртов $\mathrm{C}_{1}-\mathrm{C}_{4}$ с поверхности оксидов индия, галлия, алюминия и кремния в целях получения информации о количестве спирта, сохраняющегося на поверхности указанных оксидов после их пребывания в спиртовой среде.

\section{Экспериментальная часть}

Исходные материалы. Адсорбентами служили: моноклинная $\beta$-модификация оксида галлия о. ч., оксид индия о. ч., аморфный оксид алюминия ч.д. а. и силикагель для хроматографии. Удельная поверхность указанных оксидов была определена по низкотемпературной адсорбции азота после их дегазирования при $300^{\circ} \mathrm{C}$, вычислена по уравнению БЭТ [ $\left.{ }^{6}\right]$ и составляла, м $^{2} / \mathrm{r}: \beta-\mathrm{Ga}_{2} \mathrm{O}_{3}-14,5 ; \mathrm{In}_{2} \mathrm{O}_{3}-3,3 ; \mathrm{Al}_{2} \mathrm{O}_{3}-50,0 ; \mathrm{SiO}_{2}-450$.

В качестве адсорбатов использовали метанол, этанол, $\boldsymbol{H}$-пропанол, изопропанол, н-бутанол, изобутанол и трет-бутанол, обезвоженные натрием.

Исследование процесса термодесорбции спиртов $\mathbf{C}_{1}-\mathbf{C}_{4}$ с поверхностных оксидов провели на примере оксида алюминия, поскольку он имеет бо́льшую по сравнению с оксидами галлия и индия удельную поверхность $\left(50 \mathrm{~m}^{2} / \Gamma\right)$ и является доступным реактивом.

Используемый адсорбент высушивали при температуре $300{ }^{\circ} \mathrm{C}$ в течение 24 ч, т. е. в таких условиях, когда только более прочно адсорбированные молекулы воды сохраняются на его поверхности [7].

Можно предположить, что подготовленная таким образом поверхность оксида алюминия по своим свойствам наиболее близка к поверхности оксидов, образующихся на полупроводниках в процессе травления 
в неводных средах и при длительном промывании в органических растворителях. При таких условиях, по всей вероятности, также образуется поверхностный оксидный слой с небольшим содержанием адсорбированной воды.

После высушивания и взвешивания образцы оксида алюминия сразу же погружали в исследуемые абсолютные спирты на 24 ч. По завершении стадии адсорбции образцы высушивали до постоянного веса при температуре, которая была на $5^{\circ} \mathrm{C}$ ниже температуры кипения исследуемого спирта.

Суммарное количество адсорбированных и десорбированных спиртов определяли весовым методом. При этом для проведения десорбции исследуемые образцы нагревали при температуре $300{ }^{\circ} \mathrm{C}$ в течение 24 ч. Более детальное исследование закономерностей десорбции спиртов с поверхности оксида алюминия было проведено на хроматографе «Хром 5 » (табл. 1).

Таблица 1

Данные по десорбции спиртов с поверхности оксида алюминия

\begin{tabular}{|c|c|c|c|c|c|c|}
\hline \multirow{2}{*}{ Адсорбат } & \multirow{2}{*}{$T_{\text {кип }},{ }^{\circ} \mathrm{C}$} & \multirow{2}{*}{\begin{tabular}{|} 
Количество \\
адсорби- \\
рованного \\
спирта, \\
$\mathrm{r} / \mathrm{M}^{2} \cdot 10^{-4}$
\end{tabular}} & \multicolumn{2}{|c|}{$\begin{array}{l}\text { Количество десорбн- } \\
\text { рованного спирта, \% }\end{array}$} & \multirow{2}{*}{$\begin{array}{c}\text { Всего, } \\
\Gamma / \mathrm{m}^{2} \cdot 10^{-4}\end{array}$} & \multirow{2}{*}{$\begin{array}{c}\text { Количество } \\
\text { недесорби- } \\
\text { рующегося } \\
\text { до } 300^{\circ} \mathrm{C} \\
\text { спирта, } \\
\text { г/ } \text { м }^{2} \cdot 10^{-5} \\
\end{array}$} \\
\hline & & & до $150^{\circ} \mathrm{C}$ & $150-300^{\circ} \mathrm{C}$ & & \\
\hline Метанол & 64,6 & 3,7 & 63,0 & 37,0 & 3,6 & 1,3 \\
\hline Этанол & 78,4 & 3,9 & 55,4 & 44,6 & 3,5 & 4,1 \\
\hline Изопропанол & 82,4 & 3,3 & 46,6 & 53,4 & 3,2 & 1,6 \\
\hline трет-Бутанол & 82,8 & 4,2 & 23,8 & 76,2 & 3,9 & 2,6 \\
\hline н-Пропанол & 97,8 & 3,2 & 23,4 & 76,6 & 2,7 & 5,9 \\
\hline Изобутанол & 99,8 & 3,0 & 7,1 & 92,9 & 2,3 & 7,3 \\
\hline $\mathrm{H}$-Бутанол & 117,5 & 3,3 & 15,8 & 84,2 & 2,8 & 7,3 \\
\hline
\end{tabular}

Исследование процесса термодесорбции изоспиртов с поверхности оксидов индия, галлия, алюминия и кремния провели на примере изопропанола, так как он является одним из наиболее распространенных растворителей, используемых в технологии изготовления полупроводниковых приборов. Кроме того, как показали результаты опытов (табл. 1), поверхность оксидов после применения изопропанола загрязняется углеродными примесями значительно меньше, чем после применения других спиртов, за исключением метанола.

Таблица 2

Данные по адсорбции и десорбции изопропанола с поверхности исследованных оксидов

\begin{tabular}{|c|c|c|c|c|c|c|c|c|c|c|}
\hline \multirow{2}{*}{ Оксид } & \multicolumn{2}{|c|}{$\begin{array}{l}\text { Количество } \\
\text { адсорбиро- } \\
\text { ванного } \\
\text { изопропанола }\end{array}$} & \multicolumn{4}{|c|}{$\begin{array}{l}\text { Количество десорбированного } \\
\text { изопропанола в различные } \\
\text { температурные интервалы, \% }\end{array}$} & \multicolumn{2}{|c|}{ Bcero } & \multicolumn{2}{|c|}{$\begin{array}{l}\text { Количество } \\
\text { недесорби- } \\
\text { рующегося } \\
\text { до } 300^{\circ} \mathrm{C} \\
\text { изопропанола }\end{array}$} \\
\hline & $\begin{array}{l}t \\
\vdots \\
\vdots \\
\vdots\end{array}$ & $\begin{array}{l}\frac{1}{0} \\
\frac{a}{2} \\
\frac{2}{L}\end{array}$ & $\begin{array}{l}0 \\
8 \\
0 \\
\vdots \\
1\end{array}$ & $\begin{array}{l}0 \\
0 \\
0 \\
1 \\
0 \\
0\end{array}$ & $\begin{array}{l}0 \\
0 \\
8 \\
0 \\
1 \\
0 \\
10\end{array}$ & $\begin{array}{l}0 \\
\vdots \\
0 \\
1 \\
0 \\
\text { ¿े }\end{array}$ & $\begin{array}{l}T \\
\vdots \\
\vdots \\
\vdots\end{array}$ & $\frac{1}{\frac{1}{2}}$ & $\begin{array}{l}I \\
\vdots \\
\dot{\vdots} \\
\end{array}$ & $\frac{0}{0}$ \\
\hline $\begin{array}{l}\mathrm{In}_{2} \mathrm{O}_{3} \\
\mathrm{\beta}-\mathrm{Ga}_{2} \mathrm{O}_{3} \\
\mathrm{Al}_{2} \mathrm{O}_{3} \\
\mathrm{SiO}_{2}\end{array}$ & $\begin{array}{r}7,6 \\
37,4 \\
166,0 \\
894,0\end{array}$ & $\begin{array}{l}2,3 \\
2,6 \\
3,3 \\
2,0\end{array}$ & $\begin{array}{l}17,5 \\
30,4 \\
36,2 \\
86,9\end{array}$ & $\begin{array}{c}0 \\
12,4 \\
10,4 \\
10,8\end{array}$ & $\begin{array}{r}82,2 \\
51,7 \\
43,4 \\
0,2\end{array}$ & $\begin{array}{r}0,3 \\
5,5 \\
10,0 \\
2,1\end{array}$ & $\begin{array}{r}7,5 \\
36,6 \\
158,8 \\
893,0\end{array}$ & $\begin{array}{l}2,2 \\
2,5 \\
3,2 \\
2,0\end{array}$ & $\begin{array}{r}0,1 \\
0,8 \\
7,9 \\
1,0\end{array}$ & $\begin{array}{l}0,3 \\
0,6 \\
1,6 \\
0,025\end{array}$ \\
\hline
\end{tabular}


Все опыты, включая термообработку оксидов, проводили по вышеописанной методике.

Процесс термодесорбции также исследовали на хроматографе «Хром 5». Составы выделенных фракций определяли на хроматографе «Биохром 1 »

Анализ состава десорбированной фазы показал, что с поверхности оксидов индия, галлия и алюминия изопропанол десорбируется без разложения примерно до $200{ }^{\circ} \mathrm{C}$. Начиная с указанной температуры в продуктах десорбции в основном наблюдается пропилен. В случае оксида галлия в состав продуктов разложения входят еще ацетон и димеры пропилена.

При десорбции изопропанола с поверхности оксида кремния его разложение начинается уже при $100^{\circ} \mathrm{C}$. При $150^{\circ} \mathrm{C}$ примерно половина десорбирующегося при этой температуре изопропанола дегидратируется на пропилен. С повышением температуры количество пропилена в продуктах десорбции увеличивается.

Количественные данные о десорбции изопропанола с поверхности исследованных оксидов представлены в табл. 2.

\section{Обсуждение результатов}

При выяснении закономерностей адсорбции и десорбции различных спиртов с поверхности оксида алюминия было установлено, что адсорбирующееся на единице $\left(\mathrm{M}^{2}\right)$ его поверхности количество спирта $\mathrm{C}_{1}-\mathrm{C}_{4}$ относительно мало зависит от структуры и величины молекулы адсорбата и колеблется в пределах $(3-4,2) \cdot 10^{-4} \mathrm{r} / \mathrm{m}^{2}$, но количество органического материала, сохраняющегося на единице поверхности оксида, сильно зависит от строения молекулы спирта и от числа углеродных атомов в нем. Для спиртов с неразветвленной углеродной цепью количество недесорбирующихся при нагреве до $300^{\circ} \mathrm{C}$ органических примесей увеличивается в следующем ряду:

$$
\text { метанол< }<\text { танол < пропанол <бутанол, }
$$

т. е. повышается с ростом числа углеродных атомов в молекуле с $1,3 \cdot 10^{-5} \mathrm{r} / \mathrm{M}^{2}$ для метанола до $7,3 \cdot 10^{-5} \mathrm{r} / \mathrm{M}^{2}$ для $\mathrm{H}$-бутанола. В этом же ряду повышается и количество спирта, десорбирующегося при более высоких температурах (от $150-300^{\circ} \mathrm{C}$ ). Оно составляет $37,0 \%$ для метанола и $84,2 \%$ для $\boldsymbol{H}$-бутанола. Соответственно снижается количество десорбирующегося до $150{ }^{\circ} \mathrm{C}$ спирта.

В ряду спиртов с изостроением количество неудаляемого термообработкой органического материала до $300{ }^{\circ} \mathrm{C}$ повышается также с увеличением количества углеродных атомов в молекуле и составляет $1,6 \cdot 10^{-5} \mathrm{r} / \mathrm{m}^{2}$ для изопропанола и $7,3 \cdot 10^{-5} \mathrm{r} / \mathrm{M}^{2}$ для изобутанола. В ряду бутанолов с разным строением количество недесорбирующихся компонентов увеличивается в ряду:

$$
\text { трет-бутанол< <зобутанол }(2 \text {-метилпропанол) } \leqslant \text {-бутанол. }
$$

Надо еще отметить, что вторичные (изопропанол) и третичные (третбутанол) спирты удаляются с поверхности легче, чем соответствующие им по числу углеродных атомов первичные спирты, хотя и здесь наблюдается та же самая закономерность, что и в случае первичных спиртов, - с увеличением числа углеродных атомов в спирте количество сохранившихся на поверхности адсорбента органических примесей увеличивается. Более полную десорбцию изопропанола и трет-бутанола с поверхности оксида можно объяснить пониженной способностью указан- 
ных молекул образовывать координационную связь из-за пространственных затруднений.

Данные исследования адсорбции и десорбции изопропанола на поверхности различных оксидов (табл. 2) показывают, что изопропанол адсорбируется на различных оксидах почти одинаково: $(2-3) \cdot 10^{-4} \mathrm{r} / \mathrm{m}^{2}$, т. е. в пределах $0,5 \ldots 0,8$ монослоя (при вычислении числа монослоев посадочная площадка молекулы изопропанола была принята равной $\left.22 \AA^{2}\left[{ }^{8}\right]\right)$. Количество недесорбировавшегося до $300^{\circ} \mathrm{C}$ изопропанола сильно зависит от характера адсорбента и снижается в ряду:

$$
\mathrm{A}_{2} \mathrm{O}_{3}>\beta-\mathrm{Ga}_{2} \mathrm{O}_{3}>\mathrm{In}_{2} \mathrm{O}_{3}>\mathrm{SiO}_{2} .
$$

При этом следует подчеркнуть, что на единице поверхности оксида индия, подвергнутого нагреванию при $300^{\circ} \mathrm{C}$ в течение 24 ч, сохраняется в десять раз больше органических примесей, чем на единице поверхности оксида кремния, обработанного в тех же условиях. Для оксидов галлия и алюминия эта разница еще больше. Кроме того, если с поверхности оксида кремния до $150{ }^{\circ} \mathrm{C}$ удаляется $97,7 \%$ изопропанола, то с поверхности оксидов индия, галлия и алюминия в этих же условиях - только $17,5,42,8$ и $46,6 \%$ соответственно.

Вышеизложенное убедительно показывает, что молекулы изопропанола адсорбируются на оксидах галлия, индия и алюминия достаточно прочно и сохраняются там даже после нагревания адсорбента до $300{ }^{\circ} \mathrm{C}$ в течение длительного времени. Это может вызвать гораздо большую загрязненность поверхности полиметаллидных полупроводников (InP, $\mathrm{GaP}, \mathrm{GaAs}, \mathrm{GaAlAs}$, InGaAsP и др.) углеродными примесями после их химической обработки в спиртовых средах по сравнению с поверхностью кремния. Полученные результаты хорошо согласуются с литературными данными в том, что с кремниевых пластин растворители десорбируются, a c арсенида галлия нет [3]. Наличие спирта на поверхности InP после его травления в бром-метаноле впервые отмечено в [ $\left.{ }^{9}\right]$.

\section{ЛИТЕРА Т У А}

1. Guivarc'h, A., L'Haridon, H., Pelous, G. Chemical cleaning of InP surfaces. Oxide composition and electrical properties. - J. Appl. Phys., 1984, 55, N 4, 1139-1148.

2. Somogyi, M. Study on the possibility of native oxide removal from GaP and GaAs surface by etching, using model experiments. - Cryst. Res. Technol., 1982, 17, N $9,1129-1134$

3. Луфт Б. Д., Перевоциков В. А., Возмиљова Л. Н., Свердлин М. А., Марин К. Г. Физико-хнмические методы обработки поверхности полупроводников. М., 1982.

4. Шиляева Л. П. Кислотные, каталитические и адсорбционные свойства оксидов иттрия, галлия и индия. - В кн.: Реакционная способность веществ. M., 1977, $3-7$.

5. Киселев В. Ф. Поверхностные явления в полупроводниках и диэлектриках. М., 1970.

6. Экспериментальные методы исследования катализа, М., $1972,50$.

7. Вийра Я. Влияние термообработки на состояние гидратного покрова оксидов алюмнния, галлия и индия. - Изв. АН ЭССР. Хим., 1985, 34, № 2, 120-125.

8. Palm, U., Past, V. Füüsikaline keemia. Tallinn, 1974, 433.

9. Sasse, H.-E., König, U. ESCA - Untersuchung der Oxidation von III-V-Verbindungshalbleitern, - Fresenius Z. Anal. Chem., 1984, 319, N 6-7, 872-876.

Ннститут термофизики и электрофизики Академии наук Эстонской ССР

\section{Поступила в редакцию} 26/XI 1986 


\section{ALKOHOLIDE DESORPTSIOON AIIIBV-TOOPI POOLJUHTIDE PINNA OKSIIDIDELT}

On uuritud alkoholide $\mathrm{C}_{1}-\mathrm{C}_{4}$ termodesorptsiooni seaduspärasusi $\operatorname{In}_{2} \mathrm{O}_{3}, \mathrm{Ga}_{2} \mathrm{O}_{3}$ ja $\mathrm{Al}_{2} \mathrm{O}_{3}$ pinnalt ja tuvastatud, et pinnaühikule adsorbeeruva alkoholi hulk sōltub suhteliselt vähe uuritud adsorbentide ja adsorbaatide iseloomust. Pinnalt mitteeemalduva adsorbaadi hulk proovi kuumutamisel 24 tunni vältel $300^{\circ} \mathrm{C}$ juures oleneb nii oksiidi kui ka alkoholi laadist. Pärast mainitud tingimustel toimunud termodesorptsiooni säilib uuritud oksiidide pinnal kõige vähem metanooli ja isopropanooli.

\section{i. ARRO, Virginia ARRO, J. VIIRA}

\section{INVESTIGATION ON THE DESORPTION OF ALCOHOLS FROM AIIBV-TYPE SEMICONDUCTOR SURFACE OXIDES}

The regularities for thermodesorption of alcohols $\mathrm{C}_{1}-\mathrm{C}_{4}$ from the surface of $\mathrm{In}_{2} \mathrm{O}_{3}$, $\mathrm{Ga}_{2} \mathrm{O}_{3}$ and $\mathrm{Al}_{2} \mathrm{O}_{3}$ have been studied. It has been established that the amount of adsorbing alcohol per surface unit depends comparatively little on the nature of the adsorbents and adsorbates studied. The amount of the adsorbate not leaving the surface at heating the sample for $24 \mathrm{~h}$ at $300^{\circ} \mathrm{C}$ depends on the nature of oxides and alcohols.

The smallest amount of adsorbates stored on the surface of oxides after the thermodesorption under the described conditions is that of methanol and isopropanol. 